\title{
Making Connections across 30 Years of Family Violence Research: an Introductory Editorial
}

\author{
Rebecca J. Macy ${ }^{1}$
}

Published online: 9 June 2017

(C) Springer Science+Business Media, LLC 2017

Over thirty years ago, Drs. Vincent B. Van Hasselt and Michel Hersen launched the Journal of Family Violence (JOFV) to promote research on the significant, pernicious, and widespread problem of violence within the family (Van Hasselt and Hersen 1986). At that time, scholarly attention to family violence was just beginning, and these scholars recognized the need "for a central publication" to disseminate research "on all aspects of family violence" (Van Hasselt and Hersen 1986, p. 2). Accordingly, Drs. Van Hasselt and Hersen were among the first to provide a forum for studies on family violence including child abuse and maltreatment, dating and intimate partner violence (IPV), elder abuse, and others. With notable foresight when establishing JOFV, Drs. Van Hasselt and Hersen acknowledged the connections among the various forms of family violence. Likewise, these scholars asserted the value of bringing to bear various disciplinary and professional perspectives when investigating, preventing, addressing, and understanding family violence in all its varied forms.

After 30 years, the need for such a scholarly forum continues. For example, statistics from the United States found there were 683,000 victims of reported child abuse and neglect in 2015, with 1670 children dying from abuse and neglect in that same year (U.S. Department of Health and Human Services [USDHHS] 2017). National IPV research shows than more than one-third (35.6\%) of women experience lifetime rape, sexual assault, physical violence, and/or stalking by an intimate partner (Breiding et al. 2014). Moreover, estimates of the twelve-month prevalence of elder abuse in the

Rebecca J. Macy

rjmacy@email.unc.edu

1 School of Social Work, University of North Carolina, Chapel Hill, NC, USA
United States are about 10\% (Lachs and Pillemer 2015). Such research findings show that family violence remains a significant problem in the United States.

Of course, the problem of family violence is also global. As the World Health Organization (WHO) reports, for example, $30 \%$ of all women who have been in a relationship experience physical and/or sexual violence by intimate partners worldwide (WHO, 2013). Although this brief summary here only highlights a few key findings concerning the current state of family violence, such examples illustrate how family violence continues to be pervasive and prevalent thirty years after the establishment of JOFV. Thus, research on family violence in all its forms continues to be urgently needed.

Along with research findings signaling that family violence continues to be a serious and worldwide problem, there is a call among violence scholars to investigate the connections and relationships among various forms of violence victimization and perpetration (e.g., Hamby and Grych 2013). Likewise, the Centers for Disease Control and Prevention urge practitioners and researchers to "connect the dots" among multiple forms of violence to leverage prevention and intervention strategies to ameliorate multiple forms of violence using coordinated efforts and approaches (Wilkins et al. 2014). These recent calls echo and resonate with the vision that Drs. Van Hasselt and Hersen had when establishing JOFV.

Such calls also underscore that in an effort to understand and address a family violence type (e.g., child maltreatment, dating violence, IPV, elder abuse), practitioners and researchers oftentimes work on one form of family violence within "siloed" research and service fields without looking outside these silos to find comprehensive and holistic connections among family violence in all its forms. Focused approaches often entail investigating and intervening within one form of family violence in a singular way, for example 
focusing exclusively on physical IPV without also considering psychological and sexual IPV. No doubt, such focused approaches have yielded important scholarship, research findings, and intervention strategies. Focused approaches also facilitate deep understandings of the various types family violence. Consequently, focused research efforts will certainly continue to be necessary and important.

Nevertheless, the time is now right to build and extend from the past 30 years of family violence research to investigate how various forms of family violence are dynamically interrelated. In turn, innovative scholarly efforts that focus on such interrelationships can advance holistic understandings of and comprehensive interventions for family violence. With high numbers of family violence persisting worldwide, researchers are urged to undertake ground-breaking investigations as well as develop creative interventions to leverage factors connecting and maintaining the various forms of family violence.

For all these reasons, JOFV will especially welcome scholarship that seeks to make connections among various forms of family violence to help advance scientific understandings of and help find effective solutions for family violence. Such scholarly efforts will require diverse perspectives and creative approaches, which in turn will help to prevent and ameliorate family violence more effectively than ever before. Accordingly, this journal's aims include both promoting and providing a forum for creative, diverse, and novel family violence scholarship. JOFV also welcomes studies on families in all their various forms and diversities.

JOFV strongly encourages submissions from scholars worldwide from all disciplines and backgrounds because family violence is a global problem requiring solutions from varied perspectives and approaches. JOFV is especially interested in publishing research using innovative methods and transdisciplinary approaches. Transdisciplinary research is well-suited for studies investigating family violence because this approach calls on scholars from disparate disciplines to use their theories, concepts, and approaches to develop collaborative, conceptual frameworks that address shared problems in comprehensive and coordinated ways (Rosenfield 1992). Given that family violence in all its varied forms is a complicated and challenging problem requiring perspectives from a variety of disciplines and professions working together, JOFV aims to help to foster and support transdisciplinary research on family violence.

In terms of its substantive foci, JOFV welcomes scholarly articles related to the broad categories of (a) child abuse and maltreatment, (b) dating, domestic and partner violence, and (c) elder abuse. Within these categories, JOFV will emphasize research on physical violence, psychological violence, sexual violence, and homicides that occur in families. Concerning research methods, JOFV seeks to publish rigorous studies using quantitative, qualitative, and/or mixed methods. Rigorous systematic reviews, meta-analyses, and theoretical analyses that present a clear and robust methodology for their findings and conclusions are also welcome. Justifiably, definitions of and standards for rigor vary across study approaches, epistemologies, designs, and methods. Rather than promoting one set of methods or standards, JOFV will seek to publish scholarship that carefully and thoughtfully attends to consideration of rigor using the framework and methods that are most relevant for the study and research questions at hand.

This current issue of JOFV also seeks to make connections between the outgoing and incoming editorial teams. Two of the articles published in this issue (Birnbaum et al. 2016; Brownridge et al. 2016) were accepted under the previous editor, Dr. Robert Geffner. Likewise, all articles published in prior 2017 issues were also accepted under Dr. Geffner. This is the first issue for 2017 that includes articles accepted under both the incoming and outgoing editors. Thus, this issue presents an opportunity for me to acknowledge and thank Dr. Geffner and his team for their stewardship and success in developing and growing JOFV over the past several years. Their editorial efforts have also helped to advance the field of family violence in important ways, for example the recent special issue concerning perpetration of physical partner aggression. With deep appreciation, I commend their notable accomplishments and successes.

In closing, JOFV will continue the work started by Drs. Van Hasselt and Hersen and sustained by Dr. Geffner. As I respectfully step into the role of JOFV editor-in-chief, I affirm the journal's ongoing commitment to disseminating rigorous research on preventing, ending, and ameliorating all forms of family violence. JOFV also renews its commitment to being the central, global, and transdisciplinary publication for family violence in all its varied forms. By publishing and promoting innovative, creative, and rigorous family violence scholarship, JOFV seeks to make significant advancements in preventing family violence and promoting family wellbeing.

\section{Rebecca J. Macy}

Editor-in-Chief

\section{References}

Birnbaum, R., Saini, M., \& Bala, N. (2016). Canada's first integrated domestic violence court: Examining family and criminal court outcomes at the Toronto I.D.V.C. Journal of Family Violence, 1, 1-11. doi:10.1007/s10896-016-9886-z.

Breiding, M. J., Chen, J., \& Black, M. C. (2014). Intimate partner violence in the United States-2010. Atlanta, GA: National Center for Injury Prevention and Control, Centers for Disease Control and Prevention. 
Brownridge, D. A., Taillieu, T., Afifi, T., Chan, K. L., Emery, C., Lavoie, J., \& Elgar, F. (2016). Child maltreatment and intimate partner violence among indigenous and non-indigenous Canadians. Journal of Family Violence, 1, 1-13. doi:10.1007/s10896-016-9880-5.

Hamby, S., \& Grych, J. (2013). The web of violence: Exploring connections among different forms of interpersonal violence and abuse. Middletown, DE: Springer.

Lachs, M. S., \& Pillemer, K. A. (2015). Elder abuse. New England Journal of Medicine, 373, 1947-1956. doi:10.1056/NEJMra1404688.

Rosenfield, P. L. (1992). The potential of transdisciplinary research for sustaining and extending linkages between the health and social sciences. Social Science \& Medicine, 35(11), 1343-1357. doi:10. 1016/0277-9536(92)90038-R.
U.S. Department of Health \& Human Services [USDHHS]. (2017). Child maltreatment 2015. Washington, DC: Author.

Van Hasselt, V. B., \& Hersen, M. (1986). Introductory statement. Journal of Family Violence, 1, 1-2. doi:10.1007/BF00977027.

Wilkins, N., Tsao, B., Hertz, M., Davis, R., \& Klevens, J. (2014). Connecting the dots: An overview of the links among multiple forms of violence. Atlanta, GA/Oakland, CA: National Center for Injury Prevention and Control, Centers for Disease Control and Prevention/Prevention Institute.

World Health Organization [WHO]. (2013). Global and regional estimates of violence against women: Prevalence and health effects of intimate partner violence and non-partner sexual violence. Geneva, Switzerland: Author 